\title{
The role of Thl/Th2/Th17 cytokines and antioxidant defense system in mediating the effects of lemon and grapefruit peel hydroethanolic extracts on adjuvant-induced arthritis in rats
}

\author{
Osama M. Ahmed, Mohamed B. Ashour, Hanaa I. Fahim, Noha A. Ahmed* \\ Physiology Division, Zoology Department, Faculty of Science, Beni-Suef University, Beni-Suef, Egypt.
}

\begin{tabular}{|c|c|}
\hline ARTICLE INFO & ABSTRACT \\
\hline $\begin{array}{l}\text { Received on: } 20 / 07 / 2018 \\
\text { Accepted on: } 12 / 09 / 2018 \\
\text { Available online: } 31 / 10 / 2018\end{array}$ & $\begin{array}{l}\text { The present investigation was performed to assess the effects of lemon and grapefruit peel hydroethanolic extracts } \\
\text { on arthritic indices, T helper (Th) } 1 / \mathrm{Th} 2 / \mathrm{Th} 17 \text { cytokines, oxidative stress, and antioxidant defense system in arthritic } \\
\text { rats. The male Wistar rats, with rheumatoid arthritis induced by subcutaneous injection of } 0.2 \mathrm{ml} \text { Freund's complete } \\
\text { adjuvant into a footpad of the right hind leg on two consecutive days, were orally treated with lemon and grapefruit }\end{array}$ \\
\hline $\begin{array}{l}\text { Key words: } \\
\text { Rheumatoid arthritis, } \\
\text { lemon and grapefruit } \\
\text { peel, hydroethanolic } \\
\text { extract, oxidative stress, } \\
\text { inflammation, cytokines. }\end{array}$ & 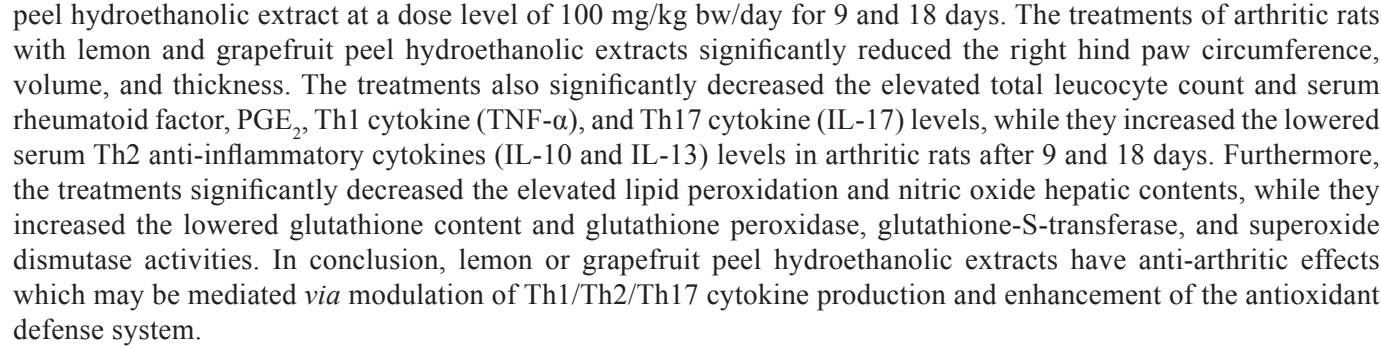 \\
\hline
\end{tabular}

\section{INTRODUCTION}

Rheumatoid arthritis (RA) is a long-term auto-immune disorder and inflammation that mainly affects the synovial membrane, cartilage, and bone (McInnes and Schett, 2007). Nearly $1 \%$ of the world's population is affected with RA, which is considered as one of the main reasons of increased death rate (Firestein, 2003).

T helper $1(\mathrm{Th} 1) / \mathrm{T}$ helper $2(\mathrm{Th} 2)$ paradigm plays a central role in the initiation and perpetuation of RA (Ahmed et al., 2017; 2018; Cañete et al., 2000; Schulze-Koops and Kalden, 2001). $\mathrm{CD}^{+} \mathrm{T}$ cells included two subsets according to their

\footnotetext{
${ }^{*}$ Corresponding Author

Noha A. Ahmed, Physiology Division, Zoology Department, Faculty of Science, Beni-Suef University, Beni-Suef, Egypt.

E-mail:drnohascience@science.bsu.edu.eg
}

cytokine production profiles, Th1 and Th2 (Abbas et al., 1996). Thus, the Th1 and Th2 cytokine balance has been a subject of curiosity for many investigators as it is assumed that the degree of polarization and heterogeneity of $\mathrm{T}$ cell lymphocytes may play a vital role in the onset and development of synovial inflammation in RA (Ahmed et al., 2017; 2018).

Tumor necrosis factor- $\alpha$ (TNF- $\alpha$ ) which is the most significant Th1 cytokine has been reported to be a target for the therapy of RA (McInnes and Schett, 2007). Interestingly, the positive results in collagen-induced arthritic rat models were obtained from investigating cytokines network interruption by anti-TNF- $\alpha$ antibodies (Williams et al., 1994). Other cytokines are being examined as targets in the dispensary with valuable results (Maini and Taylor, 2000; McInnes and Liew, 2005). Accordingly, these results provide a substantial effectiveness of the pre-clinical models that produced the roles for cytokines in the pathology of this illness and others (McInnes and Schett, 2011). 
Th2 subset is characterized by the secretion of interleukin-3 (IL-3), IL-4, IL-5, IL-9, and IL-13, which mediates humoral responses. Murine Th2 cells do also express IL-10, whereas IL-10 in human beings could not be assigned to either Th1 or Th2 subset (Schmidt-Weber et al., 1999; Sornasse et al., 1996). IL-10 is able to alleviate pathological auto-immune inflammation via inhibiting various facets of immune response (Schulze-Koops and Kalden, 2001). It suppresses the production of pro-inflammatory cytokines such as TNF- $\alpha$, IL-1 $\beta$, IL-6, IL-8, IL-12, and interferon- $\gamma$ (IFN- $\gamma$ ) by the macrophage. In addition, IL-10 reduces the production of nitric oxide (NO) and prostaglandin E2 (PGE2) in macrophages (Schulze-Koops and Kalden, 2001). Thus, it is counted as a potent anti-inflammatory cytokine (Fiorentino et al., 1991; Kang et al., 2009; Lin et al., 2017).

IL-17 is the signature cytokine of the modern term of Th17 population and has been involved in the pathogenesis of many autoimmune diseases comprising RA (Lubberts et al., 2003). IL-17 is the promoting member of a modern subclass of cytokines that have elevated pro-inflammatory characteristics (Schmidt-Weber et al., 2007). The investigations on rodents, mammalian cell cultures in addition to clinical settings assist a function of IL-17 in motivating RA (Gaffen, 2009; Schmidt-Weber et al., 2007). Cytokines of Th1 and Th17 are also responsible for the bone destruction near the synovial joint, whereas cytokines like IL-1, TNF- $\alpha$, and IL-17 were shown to be the main cause of matrix destruction (Lubberts et al., 2003).

Reactive oxygen species (ROS) play a crucial function in the initiation and development of inflammation and articular tissue damage in RA (Di Dalmazi et al., 2016; Henrotin et al., 2005; Yoo et al., 2016). ROS in RA is produced via two basic recurring mechanisms activated polymorphonuclear cells and ischemia-reperfusion in the inflamed joints (Taysi et al., 2002). These reactive species, if not scavenged, lead to lipid peroxidation (LPO) and can result in cell membrane deterioration. Studies with synovial fluids and tissues in RA have also depicted oxidative damage of lipoperoxidation products (Baskol et al., 2006). NO has been shown to regulate T cell functions under physiological conditions but overproduction of NO may contribute to T lymphocyte dysfunction (Onur et al., 2001; Veselinovic et al., 2014). Ueki et al. (1996) reported elevated nitrite levels in serum and synovia of patients with RA and osteoarthritis (OA).

Several experimental models have been developed in rats to assess the potential usefulness of anti-rheumatic drugs (Snekhalatha et al., 2013). One of the most common experimental models used for preclinical testing is the rat adjuvant arthritis that is presently under pre-clinical or clinical investigation (Gupta et al., 2014). The lineament of this model is trustworthy and precise, easily measurable, polyarticular inflammation, cartilage destruction, marked bone resorption, and periosteal bone proliferation (Ahmed et al., 2015).

Various remedies like non-steroidal anti-inflammatory drugs (NSAIDs) and disease modifying anti-rheumatoid drugs are beneficial for RA; up to $30 \%$ of patients fail to respond for the treatment (Helmick et al., 2008). However, in addition to being expensive, extensive utilization of these drugs is associated with serious adverse reactions such as gastric and duodenal ulcers, colitis, bleeding, perforation, stricture, and chronic problems such as iron deficiency anemia and protein loss and toxicity (Curtis and Singh, 2011). NSAIDs treatment also promotes joint destruction in arthritis and inhibits glycosaminoglycan synthesis. Natural food utilization interest has been recently increased as a result of its potency in trapping the free radicals as a result of their wide agreement (Ahmed et al., 2017; Shah et al., 2013). Accordingly, nowadays, the attention of scientists worldwide is directed toward anti-oxidant natural products and medicinal plants in the treatment and prevention of diseases due to the lower toxicity and fewer side effects (Patel et al., 2012).

The lemon is a good source of potassium, phenolics, flavonoids, and vitamin C (Bhavana et al., 2016). Other constituents of lemon include volatile oil (2.5\% of the peel), limonene, alphaterpinene, alpha-pinene, citral, coumarins, mucilage, pectins, bioflavonoids (mostly from pith and peel) (Fisher and Phillips, 2006; Miyake et al., 2007), $\gamma$-terpinene, $\beta$-pinene, myrcene, sabinene, $\alpha$-pinene, and p-cimene (Gök et al., 2015).

Grapefruits are a storehouse of vitamins such as thiamine, riboflavin, vitamins $\mathrm{C}$ and $\mathrm{E}$, niacin, and pantothenic acid and high content of dietary fiber as well as folic acid, potassium, magnesium, and calcium (Agarwal, 2013). Twenty-five compounds were identified from grapefruit peel extract of which limonene was the major constituent (Pino and Sánchez, 2000). Qiao et al detected 38 bioactive secondary metabolites in commercial coldpressed grapefruit peel extract (Qiao et al., 2008). Researchers have shown that the grapefruit has a positive effect in reducing the inflammation and pain in joints of arthritic patients, mainly in OA, due to the presence of its various nutritional components (Agarwal, 2013; Ganzera et al., 2006).

Therefore, the purpose of this study is to assess the preventive and anti-rheumatic activity of lemon and grapefruit peel hydroethanolic extracts as natural antioxidants in complete Freund's adjuvant (CFA)-induced arthritis in male Wistar rats. The roles of Th1, Th2, and Th17 cytokines, as well as an antioxidant defense system, were also investigated.

\section{MATERIALS AND METHODS}

\section{Experimental animals and housing}

Adult male Wistar rats weighing 130-150 g were used in this investigation. The animals were purchased from Helwan Station of Experimental Animals, Egyptian Organization for Biological Products and Vaccines (VACSERA), Helwan, Cairo, Egypt. They were observed for 2 weeks before the starting of the experiment to eliminate any infection. The animals were placed in polypropylene cages with perfectly aerated stainlesssteel covers in the animal house of Zoology Department, Faculty of Science, Beni-Suef University, Egypt at normal temperature $\left(20^{\circ} \mathrm{C}-25^{\circ} \mathrm{C}\right)$ and normal daily lighting cycle (10-12 hours/ day) and were administered balanced standard diet and water $\mathrm{ad}$ libitum. All animal methods are in accordance with the standard guidelines of the Experimental Animal Ethics Committee of Faculty of Science, Beni-Suef University, Egypt (Ethical Approval number: BSU/FS/2017/20). All attempts were done to minimize the suffering of animals. 


\section{Induction of arthritis}

CFA was purchased from Sigma Chemical Company (USA) and was used to induce RA in male Wistar rats. According to Ahmed et al. (2017), arthritis was induced by a double subcutaneous injection of $0.2 \mathrm{ml} \mathrm{CFA} \mathrm{into} \mathrm{a} \mathrm{footpad} \mathrm{of} \mathrm{the} \mathrm{right}$ hind leg of male rats in two consecutive days $(0.1 \mathrm{ml} /$ day $)$.

\section{Extraction of lemon and grapefruit peels}

The lemon fruits (Citrus limon) and grapefruits (Citrus paradisi) were obtained from Beni-Suef Governate local market. They were authenticated by Dr. Walaa A. Hassan, Lecturer of Flora, Botany Department, Beni-Suef University, Beni-Suef, Egypt. The fruits were washed with tap water and peeled. The peels were washed many times with tap water and distilled water, then air-dried in a dark cold room. The dried peels were grounded with an electric grinder and extracted by cold maceration in $70 \%$ aqueous ethanol till exhausting at the room temperature. After filtration, the filtrates were concentrated under reduced pressure. The dry filtrate obtained was stored at $-20^{\circ} \mathrm{C}$ until its usage for experimental evaluation.

\section{Dose preparation of lemon and grapefruit peel hydroethanolic extract}

Lemon and grapefruit peel hydroethanolic extracts at a dose level of $100 \mathrm{mg} / \mathrm{kg}$ bw were dissolved in $5 \mathrm{ml}$ of $1 \%$ carboxymethylcellulose (CMC) solution as a vehicle and were orally given by an oral gavage daily for a period of 3 weeks. According to Tag et al. (2014), the dose of the lemon peel hydroethanolic extract was chosen, while that of the grapefruit peel hydroethanolic extract was chosen as previously reported (Gupta et al., 2011; Mossa et al., 2015).

\section{Animal grouping}

Forty-eight rats were divided into four groups, each being 12 rats. Six rats of each group were sacrificed after 9 days and the other six after 18 days. These groups were designated as follows:

Group 1 (Normal group): the rats of this group received an equivalent volume of $1 \% \mathrm{CMC}$ daily for 18 days beginning from the starting period of the experiment by an oral gavage administration.

Group 2 (Arthritic control group): the rats of this group received a double subcutaneous injection of $0.1 \mathrm{ml} \mathrm{CFA} \mathrm{into} \mathrm{a}$ footpad of the right hind leg in two consecutive days and orally administered an equivalent volume of $1 \% \mathrm{CMC}$ daily for 18 days beginning from the starting period of the experiment.

Group 3 (Arthritic group treated with lemon peel extract): the rats of this group received a double subcutaneous injection of $0.1 \mathrm{ml}$ CFA into a footpad of the right hind leg in two consecutive days as group 2 and orally supplemented $100 \mathrm{mg} / \mathrm{kg}$ bw/day lemon peel hydroethanolic extract dissolved in $5 \mathrm{ml} \mathrm{1 \%}$ $\mathrm{CMC}$ through the entire experimental period.

Group 4 (Arthritic group treated with grapefruit peel extract): the rats of this group received a double subcutaneous injection of $0.1 \mathrm{ml}$ CFA into a footpad of the right hind leg in two consecutive days as group 2 and orally supplemented $100 \mathrm{mg} / \mathrm{kg}$ bw/day grapefruit peel hydroethanolic extract dissolved in $5 \mathrm{ml}$ $1 \% \mathrm{CMC}$ through the entire experimental period.

\section{Detection of right hind paw circumference}

At the end of the experimental period after adjuvant injection, the right hind paw circumference just above tarsal pad was measured as an indicator of swelling rate and paw edema in different groups by wrapping a piece of white cotton thread around the paw just above tarsal pad and measuring the circumference on a meter ruler (Ahmed et al., 2015; 2017; Olajide et al., 2009).

\section{Detection of right hind paw volume}

After performing the experimental work, the volume of the paw of the right hind leg was measured for each rat by putting a right hind paw in a falcon tube filled with saline $(0.9 \% \mathrm{NaCl})$ at known volume and the overflow of saline which express the paw swelling was measured.

\section{Measurement of right hind paw thickness}

At the end of the experimental period, the thickness of the right hind paw was regularly measured with a micrometer screw gauge before and after modeling until the end of the experiment at the mid-sagittal plane (Li et al., 2010).

\section{Hematological examination}

Total leukocyte count (TLC) was carried out by Neubauer slide using Turk's solution which is composed of gentian violet and $1 \%$ acetic acid (Miale, 1972).

Detection of oxidative stress and antioxidant defense system parameters

Liver LPO expressed by malondialdehyde (MDA) content, NO level, glutathione (GSH) content, superoxide dismutase (SOD) activity, glutathione peroxidase (GPx) activity, and glutathione-S-transferase (GST) activity were determined according to the methods of Ohkawa et al. (1979), Montgomery and Dymock (1961), Beutler (1963), Nishikimi et al. (1972), Paglia and Valentine (1967), and Habig et al. (1974), respectively.

\section{Assay of serum cytokines}

The levels of serum inflammatory cytokines prostaglandin $\mathrm{E}_{2}\left(\mathrm{PGE}_{2}\right)$, TNF- $\alpha$, and IL-17 and serum antiinflammatory cytokines IL-10 and IL-13 levels were determined using specific ELISA kits purchased from R and D systems, USA according to the manufacturer's instructions.

\section{Determination of serum rheumatoid factor (RF) level}

RF level in serum was achieved by using rat RF ELISA kit obtained from $\mathrm{R}$ and $\mathrm{D}$ systems according to the manufacturer's instruction.

\section{Statistical analysis}

Statistical analysis was done using SPSS v.20 software (SPSS Inc., Chicago, IL). The results were expressed as a mean \pm standard error (SE) and all statistical comparisons were made by Tukey's test post hoc analysis. The values of $p<0.05$ was considered significant, while values of $p>0.05$ were considered non-significant (Nie et al., 1970). 


\section{RESULTS}

The right hind paw circumference, an indicator of the swelling rate and paw edema, exhibited a significant increase $(p<0.05)$ in CFA-induced arthritic rats at 9 and 18 days recording percentage increases of $70.22 \%$ and $69.19 \%$ at 9 and 18 days, respectively, as compared with the normal control group. The treatment of the arthritic rats with lemon and grapefruit peel hydroethanolic extracts produced a significant amelioration $(p<0.05)$ of the elevated value of the right hind paw circumference recording percentage changes $-23.43 \%$ and $-19.17 \%$, respectively, at 9 and 18 days for lemon peel extract group and $-24.75 \%$ and $-21.73 \%$, respectively, for grapefruit peel extract group as compared with the arthritic control animals (Table 1).

The right hind paw volume, another indicator for paw swelling and edema, exhibited a significant increase $(p<0.05)$ at 9 and 18 days in CFA-induced arthritic rats recording percentage increases of $153.97 \%$ and $245.45 \%$, respectively, as compared with the normal control group. The treatment of the arthritic rats with lemon and grapefruit peel hydroethanolic extracts produced a significant improvement $(p<0.05)$ of the elevated right hind paw volume; the recorded percentage changes for lemon and grapefruit peel extract were $-21.05 \%$ and $-36.84 \%$, respectively, at the end of the experiment after 18 days when compared with the arthritic control animals (Table 1).

The right hind paw thickness, the third indicator for paw swelling and edema, revealed a significant increase $(p<0.05)$ in the CFA-induced arthritic rats at 9 and 18 days recording percentage increases of $76.17 \%$ and $159.21 \%$, respectively, as compared with the normal control group. The treatment of the arthritic rats with lemon peel hydroethanolic extract produced a significant decrease $(p<0.05)$ in the elevated right hind paw thickness recording percentage changes of $-28.68 \%$ and $-29.07 \%$ after 9 and 18 days, respectively, as compared with the arthritic control animals. On the other hand, the treatment of arthritic rats with grapefruit peel hydroethanolic extract induced a significant decrease $(p<0.05)$ in the right hind paw thickness at the nineth day, while it caused a non-significant change $(p>0.05)$ at the 18th day; the recorded percentage changes were $-29.07 \%$ and $-20.06 \%$, respectively, at the 9 th and 18th days of CFA-injection (Table 1).

Serum RF level showed a significant increase $(p<0.05)$ in CFA-induced arthritic rats after 9 and 18 days when compared with normal control rats; the recorded percentage changes were $+280.39 \%$ and $+479.05 \%$, respectively, after 9 and 18 days. The treatment of CFA-administered rats with lemon and grapefruit peel hydroethanolic extracts produced a marked significant amelioration $(p<0.05)$ in serum RF level after 9 and 18 days in comparison with arthritic control rats. The recorded percentage changes were $-53.35 \%$ and $-76.49 \%$, respectively, due to the treatment with lemon peel extract for 9 and 18 days, while they were $-40.45 \%$ and $-68.54 \%$ as a result of treatment with grapefruit peel extract for 9 and 18 days, respectively (Table 2).

TLC exhibited a significant increase $(p<0.05)$ in the arthritic control rats at 9 and 18 days; the recorded percentage increases were $177.82 \%$ and $195.45 \%$, respectively, as compared with the normal control group. The treatment of the arthritic rats with lemon and grapefruit peel hydroethanolic extracts 
Table 2. Effect of lemon and grapefruit peel hydroethanolic extracts on serum RF (U/ml) level in arthritic rats.

\begin{tabular}{ccccc}
\hline Parameter & \multicolumn{4}{c}{ RF (U/ml) } \\
\cline { 2 - 5 } Group & 9 days & \% Change & $\mathbf{1 8}$ days & \% Change \\
\hline Normal & $8.82 \pm 0.57^{\mathrm{a}}$ & & $9.02 \pm 0.53^{\mathrm{a}}$ & \\
Arthritic control & $33.55 \pm 2.63^{\mathrm{d}}$ & 280.39 & $52.23 \pm 2.75^{\mathrm{e}}$ & 479.05 \\
Arthritic group treated with lemon peel extract & $15.65 \pm 0.93^{\mathrm{bc}}$ & -53.35 & $12.28 \pm 0.70^{\mathrm{c}}$ & -76.49 \\
Arthritic group treated with grapefruit peel extract & $18.98 \pm 0.40^{\mathrm{ab}}$ & -40.45 & $16.43 \pm 0.47^{\mathrm{bc}}$ & -68.54 \\
\hline
\end{tabular}

Data are expressed as mean $\pm \mathrm{SE}$.

Number of animals in each group is six.

Means, which share the same superscript symbol(s), are not significantly different.

Percentage changes were calculated by comparing arthritic control with normal control and arthritic treated groups with arthritic control.

produced a significant amelioration $(p<0.05)$ of the elevated TLC; the recorded percentage changes for lemon and grapefruit peel hydroethanolic extract were $-45.92 \%$ and $-49.58 \%$ after 9 days and $-61.92 \%$ and $-59.85 \%$ after 18 days, respectively, as compared with the arthritic control animals (Table 3).

Serum $\mathrm{PGE}_{2}$ level exhibited a significant increase $(p<0.05)$ in CFA-induced arthritic rats after 9 and 18 days when compared with normal control rats; the recorded percentage changes were $+130.09 \%$ and $+240.58 \%$, respectively, at 9 and 18 days. The treatment of CFA-administered rats with lemon and grapefruit peels hydroethanolic extracts produced a significant improvement and decrease $(p<0.05)$ in serum $\mathrm{PGE}_{2}$ level after 9 and 18 days in comparison with arthritic control rats. The recorded percentage changes were $-38.79 \%$ and $-57.37 \%$, respectively, due to the treatment with lemon peel extract for 9 and 18 days, while they were $-41.21 \%$ and $-57.81 \%$ as a result of treatment with grapefruit peel extract for 9 and 18 days, respectively (Table 3 ).

Serum TNF- $\alpha$ level showed a significant elevation $(p<0.05)$ in CFA-induced arthritic rats after 9 and 18 days recording percentage changes of $+287.00 \%$ and $+308.25 \%$ as compared with normal control rats, respectively. The treatment of CFA-administered rats with both lemon and grapefruit peel hydroethanolic extracts produced a significant alleviation $(p<0.05)$ of serum TNF- $\alpha$ level after 9 and 18 days in comparison with arthritic control rats. The recorded percentage changes were $-34.23 \%$ and $-42.67 \%$, respectively, due to the treatment with lemon peel extract for 9 and 18 days, while they were $-39.61 \%$ and $-54.33 \%$ as a result of treatment with grapefruit peel extract for 9 and 18 days, respectively (Table 3 ).

Serum IL-17 level exhibited a significant increase $(p<0.05)$ in CFA-induced arthritic rats after 9 and 18 days recording percentage changes of $+440.65 \%$ and $+387.79 \%$ as compared with normal control rats, respectively. The treatment of CFA-administered rats with both lemon and grapefruit peel hydroethanolic extracts produced a significant alleviation $(p<0.05)$ of serum IL-17 level after 9 and 18 days in comparison with arthritic control rats. The recorded percentage changes were $-50.35 \%$ and $-57.43 \%$, respectively, due to the treatment with lemon peel extract for 9 and 18 days, while they were $-54.65 \%$ and $-66.71 \%$ as a result of treatment with grapefruit peel extract for 9 and 18 days, respectively (Table 4).

Serum IL-10 level showed a significant decrease $(p<0.05)$ in CFA-induced arthritic rats recording percentage changes of
$-55.51 \%$ and $-49.56 \%$, respectively, as compared with normal control rats. The treatment of CFA-administered rats with lemon and grapefruit peel hydroethanolic extracts produced a significant increase $(p<0.05)$ in serum IL-10 level after 9 and 18 days in comparison with arthritic control rats. The recorded percentage changes were $+88.57 \%$ and $+107.52 \%$, respectively, due to the treatment with lemon peel extract for 9 and 18 days, respectively, while they were $+94.25 \%$ and $+108.16 \%$ as a result of treatment with grapefruit peel extract for 9 and 18 days, respectively (Table 4).

Serum IL-13 level showed a significant decrease $(p<0.05)$ in CFA-induced arthritic rats after 9 and 18 days recording percentage changes of $-30.92 \%$ and $-35.39 \%$, respectively when compared with normal control rats. The treatment of CFA-administered rats with both lemon and grapefruit peels hydroethanolic extracts produced a significant increase $(p<0.05)$ in serum IL-13 level after 9 and 18 days in comparison with arthritic control rats. The recorded percentage changes were $+73.31 \%$ and $+55.11 \%$, respectively, due to the treatment with lemon peel extract for 9 and 18 days, while they were $+68.45 \%$ and $+54.01 \%$ as a result of treatment with grapefruit peel extract for 9 and 18 days, respectively (Table 4).

LPO expressed by MDA content showed a significant increase $(p<0.05)$ in the liver of CFA-induced arthritic rats after 9 and 18 days recording percentage changes of $+880.87 \%$ and $+1,425.00 \%$, respectively, as compared with normal control rats. The treatment of CFA-administered rats with lemon peel and grapefruit peel hydroethanolic extracts produced a significant amelioration $(p<0.05)$ in MDA content of liver after 9 and 18 days in comparison with arthritic control rats. The recorded percentage changes due to treatment with lemon peel extract for 9 and 18 days were $-72.87 \%$ and $-75.07 \%$, respectively, while they were $-74.92 \%$ and $-75.09 \%$ as a result of treatment with grapefruit extract, respectively (Table 5).

NO level showed a significant increase $(p<0.05)$ in the liver of CFA-induced arthritic rats after 9 and 18 days as compared with normal control rats; the recorded percentage changes were $+812.12 \%$ and $+1,156.00 \%$, respectively. The treatment of CFA-administered rats with lemon peel and grapefruit peel hydroethanolic extracts produced a significant decrease $(p<0.05)$ in liver NO level after 9 and 18 days in comparison with arthritic control rats. The recorded percentage changes were $-51.83 \%$ and $-41.63 \%$, respectively, due to the treatment with lemon peel extract for 9 and 18 days, while they were $-59.14 \%$ and $-45.50 \%$ as a result of treatment with grapefruit peel extract for 9 and 18 days, respectively (Table 5). 

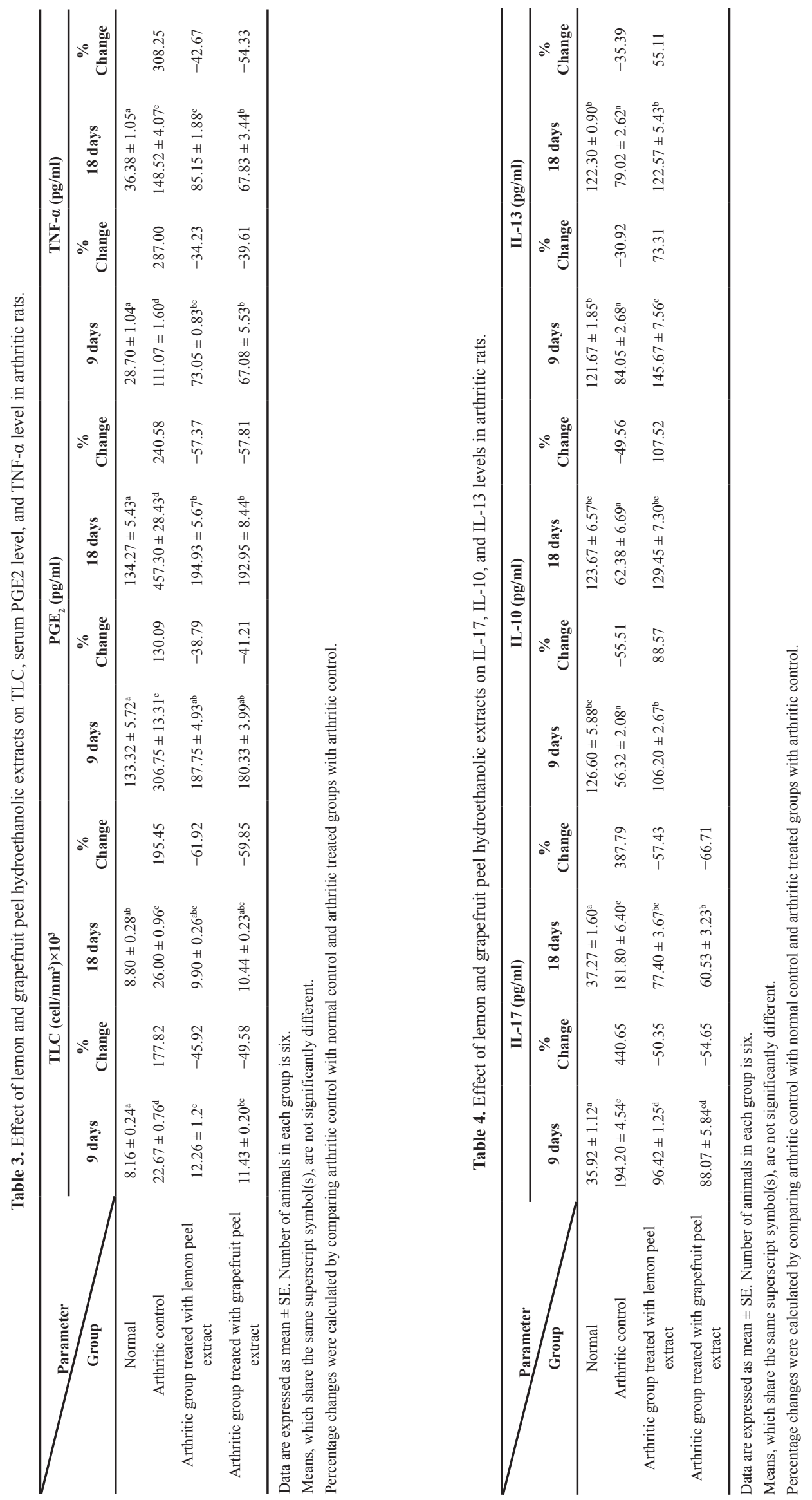
GSH content in the liver CFA-induced arthritic rats showed a significant decrease $(p<0.05)$ after 9 and 18 days when compared with normal control rats; the recorded percentage changes were $-71.83 \%$ and $-71.03 \%$, respectively. The treatment of CFA-administered rats with both lemon peel and grapefruit peel hydroethanolic extracts produced a significant elevation $(p<0.05)$ in liver GSH content after 9 and 18 days in comparison with arthritic control rats. The recorded percentage changes were $+135.45 \%$ and $+129.24 \%$, respectively, due to the treatment with lemon peel extract for 9 and 18 days, while they were $+130.71 \%$ and $+127.84 \%$ as a result of treatment with grapefruit peel extract for 9 and 18 days, respectively (Table 5).

SOD activity of CFA to albino rats exhibited a significant decrease $(p<0.05)$ in the liver after 9 and 18 days when compared with normal control rats; the recorded percentage changes were $-73.89 \%$ and $-81.25 \%$, respectively. The treatment of CFA-administered rats with lemon peel and grapefruit peel hydroethanolic extracts produced a significant $(p<0.05)$ amelioration in SOD activity of liver after 9 and 18 days in comparison with arthritic control rats. The recorded percentage changes were $+205.32 \%$ and $+266.67 \%$, respectively, due to the treatment with lemon peel extract for 9 and 18 days, while they were $+192.55 \%$ and $+265.33 \%$ as a result of treatment with grapefruit peel extract for 9 and 18 days, respectively (Table 6).

GPx activity in the liver of CFA-induced arthritic rats showed a significant decrease $(p<0.05)$ after 9 and 18 days when compared with normal control rats; the recorded percentage change were $-48.55 \%$ and $-52.79 \%$, respectively. The treatment of CFA-administered rats with lemon peel and grapefruit peel hydroethanolic extracts produced a significant alleviation in $(p<0.05)$ activity of the liver after 9 and 18 days in comparison with arthritic control rats. The recorded percentage changes were $+75.86 \%$ and $+98.54 \%$, respectively, due to the treatment with lemon peel extract for 9 and 18 days, while they were $+71.94 \%$ and $+114.26 \%$ as a result of treatment with grapefruit peel extract for 9 and 18 days, respectively (Table 6).

GST activity in liver of CFA-induced arthritic rats showed a significant decrease $(p<0.05)$ after 9 and 18 days as compared with normal control rats; the recorded percentage changes were $-24.31 \%$ and $-52.06 \%$, respectively. The treatment of CFA-administered rats with both lemon peel and grapefruit peel hydroethanolic extracts produced a significant increase $(p<0.05)$ in GST activity of the liver after 9 and 18 days in comparison with arthritic control rats. The recorded percentage changes were $+22.55 \%$ and $+74.16 \%$ due to the treatment with lemon peel extract for 9 and 18 days, while they were $+26.65 \%$ and $+91.76 \%$ as a result of treatment with grapefruit peel extract for 9 and 18 days, respectively (Table 6).

\section{DISCUSSION}

Despite the enormous research that has been carried out for RA, it still remains a disorder which can be controlled and not treated. Moreover, the severity of joint inflammation fluctuates resulting in exacerbations and remissions with a shortened life expectancy and reduced quality of life. So, the early intervention with safe treatments, which aimed at tight control of the inflammatory process to prevent irreversible joint destruction 


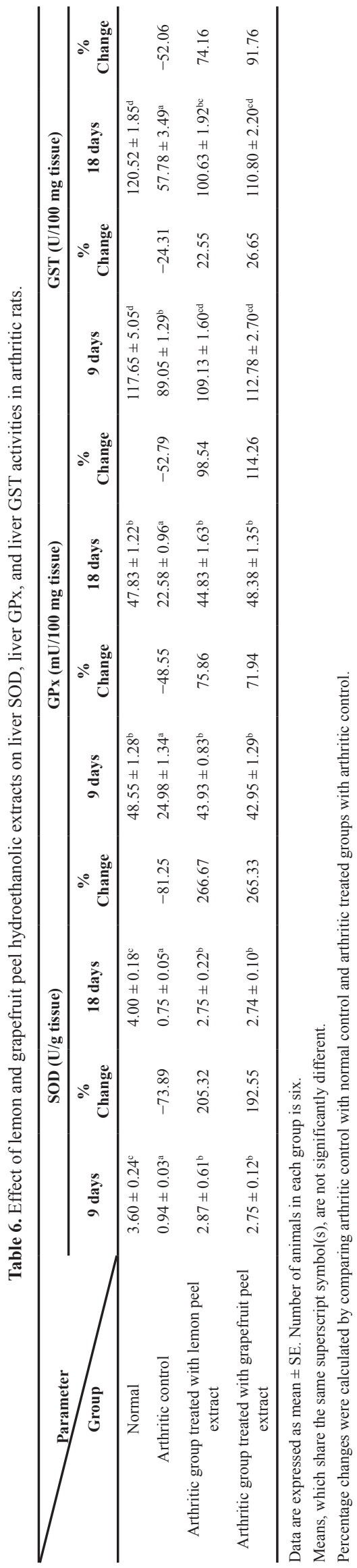

and preserve function remains efficacious. Concurrently, there is a considerable interest in the potential of immunomodulatory therapies in the treatment of immune-based inflammatory diseases. Based on these principles, the present study was conducted to evaluate the preventive and ameliorative action of lemon and grapefruit peel hydroethanolic extracts against CFA-induced arthritis through their anti-inflammatory, anti-rheumatic, and anti-oxidant efficacies after 9 and 18 days. The CFA-induced arthritic model was used as the optimum available experimental model of RA in the present study because it is a model of chronic polyarthritis with characteristics that are similar to RA in human (Vijayalaxmi et al., 2015).

In CFA experimental model, rats showed a chronic swelling in diversified joints under the effect of inflammation, erosion of joint cartilage and bone destruction, and remodeling which resemble human rheumatoid disorder. A whole devastation of joint integrity and functions are caused by these inflammatory cells in animal models. Also, the rats depicted a soft tissue swelling around the ankle joints at the time of arthritis induction (Vijayalaxmi et al., 2015).

A change in rheumatoid indices as right hind paw circumference, paw volume, and paw thickness has been utilized for assessing the anti-inflammatory effects on RA (Ali et al., 2016; Chen et al., 2017; Eiseman et al., 1982). In the present investigation, these rheumatoid indices were measured to assess the anti-arthritic activity of lemon and grapefruit peel hydroethanolic extracts at the dose level of $100 \mathrm{mg} / \mathrm{kg} / \mathrm{bw}$ in arthritic rats. In association with the increase of RF in serum, the right hind paw circumference, volume, and thickness were significantly increased in the CFA-induced arthritic rats at 9 and 18 days after CFA-injection reflecting the hind paw swelling and edema as well as inflammation. These results are in concurrence with other authors who stated that there is a strong relationship between the presence of inflammation and arthritic index (Rovenský et al., 2009). As reported by Rasool et al. (2006), the elevated paw swelling observed in the arthritic mice was found to be the cause of edema of periarticular tissues. An increase in leucocyte count, observed in arthritic rats of the present study, has been found to be associated with changes in the RF and arthritic indices; this evidence was supported by Latha et al. (1998). In the same way, as stated by past publications, there was a fast development of a localized inflammatory response distinguished by high vascular leakage and following swelling of the affected paw (Krenn et al., 2006) as well as inflamed tendons and ligament insertions (Almarestani et al., 2011). The treatment of arthritic rats with lemon and grapefruit peel hydroethanolic extracts, in this study, produced a significant reduction in the right hind paw circumference, volume, and thickness and decrease in serum RF level as compared with the arthritic control group; the grapefruit peel hydroethanolic extract seemed to be more potent. These results reflect the anti-arthritic efficacies of both extracts in this regard; the health influence and properties of lemon extract have been attributed to the presence of vitamin $\mathrm{C}$ and flavonoids, due to their radical scavenging activities (Lopes Campêlo et al., 2011; Tanaka et al., 1997). Meanwhile, the preventive effects of grapefruit extract may be attributed to its major components of antioxidant flavonoids and phenolics such as gallic and cinnamic acids, catechin, rutin as well as rosmarinic, chlorogenic, caffeic, vanillic, and coumaric acids (El Gengaihi et al., 2013). 
Biomarkers for RA are important tools for shedding the light on disease progression and to assist in finding new therapeutics for the treatment of RA. From the hematological point of view, CFA-induced arthritis in rats is familiar with being responsible for leukocytosis (Adeneye et al., 2014; Sumanth and Swetha, 2012).

Our findings indicated that the induction of arthritis with CFA is associated with an increased TLC which is in agreement with the previously published data (Sumanth and Swetha, 2012). The disorder of $\mathrm{T}$ lymphocytes and the irregular activation of mononuclear macrophages are vital in the pathogenesis of arthritis (Li et al., 2008). The leukocytosis, in the present study, is attributed to CFA which is an antigen of decreased mycobacterium tuberculosis emulsified in mineral oil and mannide mono-oleate (Stils, 2005). Additionally, the adjuvants are generally utilized to devise the immune response by the host animal to this antigen. Once the immune system is promoted, the effects of adjuvants induce inflammation due to leukocytic infiltration; thereby, leukocyte count may be elevated secondary to this inflammation and also correlate with arthritis severity (Geboes et al., 2007; Rindfleisch and Muller, 2005; Syed and Pinals, 1996).

$\mathrm{PGE}_{2}$ plays a vital role in the propagation of the inflammatory disorder. Interestingly, the biosynthesis of $\mathrm{PGE}_{2}$ is markedly proliferated in inflamed tissue and they take part in the production of the cardinal signs of severe inflammation. While the pro-inflammatory aspects of prostaglandins during the severe inflammation are well founded, their part in the resolution of the inflammatory response is a subject of debate (Ricciotti and FitzGerald, 2011). However, some previously published data suggested that at least some of the pro-inflammatory properties of RA are interceded by $\mathrm{PGE}_{2}$. Specifically, $\mathrm{PGE}_{2}$ has been attributed to the edema and the erosion of cartilage and juxtaarticular bone found in RA (Davies et al., 1984; McCoy et al., 2002). In the CFA experimental model, neutralizing $\mathrm{PGE}_{2}$ with monoclonal antibodies lowered both the signs and levels of inflammatory markers of RA (Portanova et al., 1996). In this work, the treatments of CFA-induced arthritic rats with lemon and grapefruit peel hydroethanolic extracts for 9 and 18 days significantly decreased the elevated serum levels of $\mathrm{PGE}_{2}$. Thus, the decrease in the elevated $\mathrm{PGE}_{2}$ because of treatment of arthritic rats with the peel extracts may play a role in the improvement effect of these extracts on the arthritic condition.

In this current study, the levels of the pro-inflammatory and inflammatory cytokines (TNF- $\alpha$ and IL-17) as well as the anti-inflammatory cytokines (IL-10 and IL-13) were determined in the sera of all animal groups to evaluate the anti-inflammatory effects of treatment with lemon and grapefruit peel hydroethanolic extracts for 9 and 18 days on CFA-induced arthritis. The liberation of particular cytokines into the systemic circulation has been noticed in a diversity of inflammatory disorder, including RA. Their levels are often reflecting disease seriousness. In RA, the equilibrium between pro-inflammatory and anti-inflammatory cytokines defines the degree and extent of inflammation; and thus, can lead to different clinical influences. Among murine CD4+ T cells, Two very featured cytokine secretion paradigms have been realized, namely; Th1 and Th2. Thelper 1 (Th1) cells secrete IFN- $\gamma$, TNF- $\alpha$, and IL-2, whereas T helper 2 (Th2) secrete IL-4, IL-13, and IL-10 (Romagnani, 1997). RA is an inflammatory disorder characterized by the preponderance of Th1 on Th2 and thereby the overproduction of pro-inflammatory and inflammatory cytokines. In the present study, the serum TNF- $\alpha$ exhibited a significant high level in CFA-induced arthritic rats, while serum IL-10 and IL-13 levels were decreased. These findings are in accordance with Liu et al. (2009) and Shah et al. (2013) and confirm the bias toward Th1 in CFA-induced arthritis. It has been shown that, IL-10 inhibits the output of pro-inflammatory cytokines, including IL-1, TNF- $\alpha$, and IL-2 as well as $\mathrm{NO}$ and $\mathrm{PGE}_{2}$ (Keystone et al., 1998; Persson et al., 1996) and IL-13 induces interleukin-4-independent $\operatorname{IgG}_{4}$ and $\mathrm{IgE}$ synthesis and $\mathrm{CD}_{23}$ expression by human B cells (Punnonen et al., 1993). In the current study, serum IL-13 in CFA-induced arthritis rats significantly decreased and this result is in accordance with Barra et al. (2014) and Woods et al. (1997) who found low IL-13 production in synovial fluid and tissue from patients with RA. It is worth mentioning that the Th1/Th2 paradigm gave rise to the hygiene hypothesis, suggesting that increased hygiene conditions limit Th1 reactions, which in turn allows more Th2 reactions (Schmidt-Weber et al., 2007). In agreement with this hypothesis, the present study revealed that the treatments of CFA-induced arthritic rats with lemon and grapefruit peel hydroethanolic extracts for 9 and 18 days activate the Th2 reactions and production of anti-inflammatory cytokines including IL-4, IL-10, and IL-13, while they have an inhibitory effect on the augmented Th1 reactions and production of pro-inflammatory cytokine, TNF- $\alpha$, which has a pivotal role in the pathogenesis of RA (Brennan and McInnes, 2008).

In addition to the Th1/Th2 paradigm, Th17 cells characterized by IL-17, IL-6, TNF- $\alpha$, and IL-22 expression are also involved in the progress of autoimmune diseases and RA (Bush et al., 2002; Zheng et al., 2007). Neutralization of Th17-produced pro-inflammatory cytokine, IL-17, resolves tissue pathology in autoimmune models (Rangachari et al., 2006). Furthermore, anti-IL-17 minimizes the joint damage in experimental arthritic rats (Bush et al., 2002) and lowers neutrophil infiltration in experimental asthma model (Hellings et al., 2003; Sergejeva et al., 2005). Based on these elucidations, it can be suggested that the suppressing effect of lemon and grapefruit peel hydroethanolic extracts on Th17 cells and IL-17 production in CFA-induced arthritic rats, in the present study, may play a role, at least in part, in the improvement effects on arthritic indices, leukocytosis, and RF.

The high throughput of cytokines and growth factors from the inflamed synovium may be responsible for the pathophysiology of OA. The low-grade OA synovitis is itself cytokine-driven, although the levels of pro-inflammatory cytokines are lower than in RA. In particular, TNF- $\alpha$ has been assigned as a key player in OA pathogenesis, both in synovial inflammation and in activation of chondrocytes (Goldring, 1999; Martel-Pelletier et al., 1999; Singh et al., 2014). RA can be discriminated from other shapes of polyarthritis by the effect of RF, which is an immunoglobulin $\mathrm{M}$ antiglobulin directed against immunoglobulin G (IgG) antibody (Kokkonen et al., 2011). RF, a circulating antibody to immunoglobulin $\mathrm{G}$, is a key serum analyzer used in the diagnosis of RA in addition to an assist for the prognosis of RA-severity (Chandrashekara et al., 2002; Firestein, 2003). In this investigation, the subcutaneous injection of CFA into normal male albino rats induced a significant increase in serum RF level. This result is in agreement with the results of previous literature, which 
reported similar results (Banji et al., 2011; Mythilypriya et al., 2008). The treatment of CFA-induced arthritic rats with lemon and grapefruit peel hydroethanolic extracts, on the other hand, significantly decreased the elevated serum RF reflecting their ameliorative effects on the arthritic conditions.

The actual mechanism of suppressing inflammation may be due to secondary metabolites such as flavonoids, which have been shown to be constituents of lemon and grapefruit peel hydroethanolic extracts and have both anti-inflammatory (Agarwal, 1982; Kubo et al., 1984) and anti-arthritic activities (Haqqi et al., 1999; Kubo et al., 1984).

In the present study, NO level and LPO in liver homogenate of CFA-induced arthritic rats were significantly elevated, while GSH content and GPx, GST, and SOD activities were significantly decreased. The treatment of CFA-induced arthritic rats with lemon and grapefruit peel hydroethanolic extracts produced a significant decrease in the elevated LPO and NO level and induced a significant improvement of GSH and antioxidant enzyme activities. It is worth mentioning that the antioxidants such as GSH, GPx, GST, and SOD are very important systems that protect the cell against free radicals (Bhattacharyya et al., 2014). It is also well known that endogenous anti-oxidant enzymes are responsible for preventing free radicals-induced oxidative damage by neutralizing the toxic radicals before any other molecules that can become a target (Bhattacharyya et al., 2014). In the present work, a remarkable decrease in these antioxidants in arthritic rats proves the involvement of oxidative damage in CFA-induced arthritis. Recently, it has been shown that there was a close engagement between the RA and oxidative stress in both humans and animals (Arulmozhi et al., 2011; Kamanlı et al., 2004; Seven et al., 2008).

Increased lipid peroxidation, oxidative stress, and a decrease in the enzymatic antioxidants, including GPx and SOD have been found in RA in patients and in arthritic rats (Ramezani et al., 2009; Seven et al., 2008). Our previous results depicted that high levels of ROS and oxidative stress caused the damage of cartilage in the adjuvant-induced rats (Choosri et al., 2017). Hepatic involvement has been notified in cases of RA associated with an abnormal liver function examine, a mild chronic inflammatory infiltrate of the portal tract, small foci of necrosis, and fatty liver (Abraham et al., 2004; Ruderman et al., 1997). The elevation in oxidative stress in CFA-induced arthritis in the present work may be due to a lowering in the non-enzymatic antioxidant, GSH, and enzymatic antioxidants comprising GPx, GST, and SOD activities. In consistent with this elucidation, Comar et al. (2013) showed a higher level of ROS in the liver of arthritic rats that is mainly the effect of both an enhanced pro-oxidant system and an inadequate antioxidant defense mechanism. In the present study, the lemon and grapefruit peel hydroethanolic extracts decreased oxidative stress by inhibiting free radicals' formation and increasing antioxidant enzyme activity. It is obvious that lemon and grapefruit peel hydroethanolic extracts possess anti-oxidative properties which may be due to their antioxidant constituents such as flavonoids. Based on these findings and elucidations, it can be suggested that the preventing effects of lemon and grapefruit peel hydroethanolic extracts on CFA-induced arthritis may be due, at least in part, to their ability to scavenge reactive oxygen and nitrogen species to enhance the antioxidant defense system.

\section{CONCLUSIONS}

In conclusion, lemon and grapefruit peel hydroethanolic extracts have potent anti-inflammatory effects in CFA-induced arthritic rats manifested by the activation of Th2 cells and attenuation of Th1 and Th17 cytokines production. The extracts also suppressed oxidative stress and enhanced the antioxidant defense system in CFA-induced arthritic rats. Thus, these extracts may have potential effects on the prevention and therapy of the RA which may be mediated via their modulatory effects on Th1/ Th2/Th17 cytokines and their antioxidant activities. However, further efforts are demanded to evaluate the efficacy of lemon and grapefruit peel hydroethanolic extracts in the treatment of RA in human beings.

\section{CONFLICTS OF INTEREST}

The authors declare that they have no competing interests.

\section{REFERENCES}

Abbas AK, Murphy KM, Sher A. Functional diversity of helper t lymphocytes. Nature, 1996; 383(6603):787; doi:10.1038/383787a0

Abraham S, Begum S, Isenberg D. Hepatic manifestations of autoimmune rheumatic diseases. Ann Rheum Dis, 2004; 63(2):123-9; doi:10.1136/ard.2002.001826

Adeneye AA, Oreagba AI, Ishola IO, Kalejaiye HA. Evaluation of the anti-arthritic activity of the hydroethanolic leaf extract of alchornea cordifolia in rats. Afr J Tradit Complement Altern Med, 2014; 11(2):40210; doi:10.1155/2016/1230294

Agarwal O. The anti-inflammatory action of nepitrin, a flavonoid. Agents Actions, 1982; 12(3):298-302; doi:10.1007/BF01965393

Agarwal SK. Grapefruit: a nutritional fruit fraught with danger of severe drug interactions. Drug Discov, 2013; 3(9):43-4; doi:10.2165/11585250-000000000-00000

Ahmed O, Fahim H, Mahmoud A, Ahmed E. Bee venom and hesperidin effectively mitigate complete freund's adjuvant-induced arthritis via immunomodulation and enhancement of antioxidant defense system. Arch Rheumatol, 2018; 33(2):198-212; doi:10.5606/ ArchRheumatol.2018.6519

Ahmed OM, EL-Abd SF, El Mahdi EA, Abdou EA. Curcumin ameliorative efficacy on type 1 diabetes mellitus coexisted with rheumatoid arthritis in wistar rats. Merit Res J Med Med Sci, 2015; 3(7):256-70; doi:10.1111/cei.12322

Ahmed OM, Soliman HA, Mahmoud B, Gheryany RR. Ulva lactuca hydroethanolic extract suppresses experimental arthritis via its antiinflammatory and antioxidant activities. Beni-Suef University J Basic Appl Sci, 2017; 6(4):394-408; doi:10.1016/j.bjbas.2017.04.013

Ali A, El-Zaitony A, Al-Haleem E. Evaluation of therapeutic efficacy of vinpocetine in adjuvant induced arthritis model in rats. J Pain Manage Med, 2016; 2(115):2; doi:10.4172/jpmme.1000115

Almarestani L, Fitzcharles MA, Bennett GJ, Ribeiro-da-Silva A. Imaging studies in freund's complete adjuvant model of regional polyarthritis, a model suitable for the study of pain mechanisms, in the rat. Arthritis Rheum, 2011; 63(6):1573-81; doi:10.1002/art.30303

Arulmozhi S, Mazumder PM, Sathiyanarayanan L, Ashok P. Anti-arthritic and antioxidant activity of leaves of alstonia scholaris linn. R. Br. Eur J Integr Med, 2011; 3(2):e83-90; doi:10.1016/j.eujim.2011.04.01

Banji D, Pinnapureddy J, Banji OJ, Saidulu A, Hayath MS. Synergistic activity of curcumin with methotrexate in ameliorating freund's complete adjuvant induced arthritis with reduced hepatotoxicity in experimental animals. Eur J Pharmacol, 2011; 668(1):293-8; doi:10.1016/j. ejphar.2011.06.006

Barra L, Summers K, Bell D, Cairns E. Serum cytokine profile of unaffected first-degree relatives of patients with rheumatoid arthritis. J Rheumatol, 2014; 41(2):280-5; doi:10.3899/jrheum.130539 
Baskol G, Demir H, Baskol M, Kilic E, Ates F, Karakukcu C, Ustdal M. Investigation of protein oxidation and lipid peroxidation in patients with rheumatoid arthritis. Cell Biochem Function, 2006; 24(4):307-11; doi:10.1002/cbf.1257

Beutler E. Improved method for the determination of blood glutathione. J Lab Clin Med, 1963;61:882-8; doi:10.12691/jcrt-2-3-4

Bhattacharyya A, Chattopadhyay R, Mitra S, Crowe SE. Oxidative stress: an essential factor in the pathogenesis of gastrointestinal mucosal diseases. Physiol Rev, 2014; 94(2):329-54; doi:10.1152/ physrev.00040.2012

Bhavana A, Shilpa P, Naveen G, Laxmi G, Varalaxmi N, Satyanarayana T. Phytochemical screening and possible pharmacological actions of citrus limonum methanolic leaf extract. Indo Am J Pharmaceutical Res, 2016; 6(9):6593-603; doi:10.24237/djps.1301.223C

Brennan FM, McInnes IB. Evidence that cytokines play a role in rheumatoid arthritis. J Clin Invest, 2008; 118(11):3537-45; doi:10.1172/ JCI36389

Bush KA, Farmer KM, Walker JS, Kirkham BW. Reduction of joint inflammation and bone erosion in rat adjuvant arthritis by treatment with interleukin-17 receptor igg1 fc fusion protein. Arthritis Rheum, 2002; 46(3):802-5; doi:10.1002/art.10173

Cañete JD, Martínez SE, Farrés J, Sanmartí R, Blay M, Gómez A, Salvador G, Muñoz-Gómez J. Differential th1/th2 cytokine patterns in chronic arthritis: interferon $\gamma$ is highly expressed in synovium of rheumatoid arthritis compared with seronegative spondyloarthropathies, Ann Rheum Dis, 2000; 59(4):263-8; doi:10.1136/ard.59.4.263

Carper J. Grapefruit. The Food Pharmacy: Dramatic New Evidence That Food is Your Best Medicine. Bantam Books, New York, NY, pp 213-5, 1988.

Chandrashekara S, Anilkumar T, Jamuna S. Complementary and alternative drug therapy in arthritis. J Assoc Physicians India, 2002; $50: 225-7$

Chen Y, Wang QW, Zuo J, Chen JW, Li X. Anti-arthritic activity of ethanol extract of claoxylon indicum on freund's complete adjuvant-induced arthritis in mice. BMC Complement Altern Med, 2017; 17(1):11; doi:10.1186/s12906-016-1500-7

Choosri N, Tanasawet S, Chonpathompikunlert P, Sukketsiri W. Apium graveolens extract attenuates adjuvant induced arthritis by reducing oxidative stress. J Food Biochem, 2017; 41(1); doi:10.1111/jfbc.12276

Comar JF, de Sá-Nakanishi AB, de Oliveira AL, Wendt MMN, Amado CAB, Iwamoto ELI, Peralta RM, Bracht A. Oxidative state of the liver of rats with adjuvant-induced arthritis, Free Radic Biol Med, 2013; 58:144-53; doi:10.1016/j.freeradbiomed.2012.12.003

Curtis JR, Singh JA. Use of biologics in rheumatoid arthritis: current and emerging paradigms of care. Clin Ther, 2011; 33(6):679-707; doi:10.1016/j.clinthera.2011.05.044

Davies P, Bailey PJ, Goldenberg MM, Ford-Hutchinson AW. The role of arachidonic acid oxygenation products in pain and inflammation. Ann Rev Immunol, 1984; 2(1):335-57; doi:10.1146/annurev. iy.02.040184.002003

Di Dalmazi G, Hirshberg J, Lyle D, Freij JB, Caturegli P. Reactive oxygen species in organ-specific autoimmunity. Auto Immun Highlights, 2016; 7(1):11; doi:10.1007/s13317-016-0083-0

Eiseman JL, Von Bredow J, Alvares AP. Effect of honeybee (apis mellifera) venom on the course of adjuvant-induced arthritis and depression of drug metabolism in the rat. Biochem Pharmacol, 1982; 31(6):1139-46; doi:10.1016/0006-2952(82)90354-9

El Gengaihi S, Ella FA, Hassan EM, Shalaby EA, Baker DA. Phytochemical investigation and radical scavenging activity of wastes of some grape varieties grown in Egypt. Global J Pharmacol, 2013; 7(4):46573; doi:10.5829/idosi.gjp.2013.7.4.1115

Fiorentino, DF, Zlotnik A, Mosmann T, Howard M , O'garra A. Il-10 inhibits cytokine production by activated macrophages. J Immunol, 1991; 147(11):3815-22; doi:10.1084/jem.174.5.1209

Firestein GS. Evolving concepts of rheumatoid arthritis. Nature, 2003; 423(6937):356-61; doi:10.1038/nature01661
Fisher K, Phillips CA. The effect of lemon, orange and bergamot essential oils and their components on the survival of campylobacter jejuni, escherichia coli o157, listeria monocytogenes, bacillus cereus and staphylococcus aureus in vitro and in food systems. J Appl Microbiol, 2006; 101(6):1232-40; doi:10.1111/j.1365-2672.2006.03035.x

Gaffen SL. The role of interleukin-17 in the pathogenesis of rheumatoid arthritis. Curr Rheumatol Rep, 2009; 11(5):365.

Ganzera M, Aberham A, Stuppner H. Development and validation of an hplc/uv/ms method for simultaneous determination of 18 preservatives in grapefruit seed extract. J Agric Food Chem, 2006; 54(11):3768-72; doi:10.1021/jf060543d

Geboes L, Klerck BD, Balen MV, Kelchtermans H, Mitera T, Boon L, Wolf-Peeters CD, Matthys P. Freund's complete adjuvant induces arthritis in mice lacking a functional interferon- $\gamma$ receptor by triggering tumor necrosis factor $\alpha$-driven osteoclastogenesis. Arth Rheum, 2007; 56(8):2595-607; doi:10.1002/art.22791

Gök A, İsmail Kirbaşlar S, Gülay Kirbaşlar F. Comparison of lemon oil composition after using different extraction methods. J Essential Oil Res, 2015; 27(1):17-22.

Goldring MB. The role of cytokines as inflammatory mediators in osteoarthritis: lessons from animal models. Connect Tiss Res, 1999, 40(1):1-11; doi:10.3109/03008209909005273

Gupta M, Sasmal S, Mukherjee A. Therapeutic effects of acetone extract of saraca asoca seeds on rats with adjuvant-induced arthritis via attenuating inflammatory responses. Int Scholarly Res Network Rheumatol, 2014; 2014:1-12; doi:10.1155/2014/959687

Gupta V, Kohli K, Ghaiye P, Bansal P, Lather A. Pharmacological potentials of citrus paradise - an overview. Int J Phytother Res, 2011; $1(1): 8-17$.

Habig WH, Pabst MJ, Jakoby WB. Glutathione s-transferases the first enzymatic step in mercapturic acid formation. J Biol Chem, 1974; 249(22):7130-9.

Haqqi TM, Anthony DD, Gupta S, Ahmad N, Lee MS, Kumar GK, Mukhtar H. Prevention of collagen-induced arthritis in mice by a polyphenolic fraction from green tea. Proc NatlAcad Sci, 1999; 96(8):4524-9; doi:10.1073/pnas.96.8.4524

Hellings PW, Kasran A, Liu Z, Vandekerckhove P, Wuyts A, Overbergh L, Mathieu C, Ceuppens JL. Interleukin-17 orchestrates the granulocyte influx into airways after allergen inhalation in a mouse model of allergic asthma. Am J Respir Cell Mol Biol, 2003; 28(1):42-50; doi: $10.1165 / \mathrm{rcmb} .4832$

Helmick CG, Felson DT, Lawrence RC, Gabriel S, Hirsch R, Kwoh CK, Liang MH, Kremers HM, Mayes MD, Merkel PA. Estimates of the prevalence of arthritis and other rheumatic conditions in the united states: Part I. Arth Rheum, 2008; 58(1):15-25; doi:10.1002/art.23177

Henrotin Y, Kurz B, Aigner T. Oxygen and reactive oxygen species in cartilage degradation: Friends or foes? Osteoarthritis Cartilage, 2005; 13(8):643-54; doi:10.1016/j.joca.2005.04.002

Kamanlı A, Nazıroğlu M, Aydılek N, Hacievlıyagil C. Plasma lipid peroxidation and antioxidant levels in patients with rheumatoid arthritis Cell Biochem Function, 2004; 22(1):53-7; doi:10.1002/cbf.1055

Kang JW, Choi SC, Cho MC, Kim HJ, Kim JH, Lim JS, Kim SH, Han JY, Yoon DY. A proinflammatory cytokine interleukin-32 $\beta$ promotes the production of an anti-inflammatory cytokine interleukin-10. Immunology, 2009; 128(1pt2); doi:10.1111/j.1365-2567.2008.03025.x

Keystone E, Wherry J, Grint P. Il-10 as a therapeutic strategy in the treatment of rheumatoid arthritis. Rheum Dis Clin North Am, 1998; 24(3):629-39; doi:10.1016/S0889-857X(05)70030-2

Kokkonen H, Mullazehi M, Berglin E, Hallmans G, Wadell G, Rönnelid J, Rantapää-Dahlqvist S. Antibodies of igg, iga and igm isotypes against cyclic citrullinated peptide precede the development of rheumatoid arthritis. Arth Res Ther, 2011; 13(1):R13; doi:10.1186/ar3237

Krenn V, Morawietz L, Burmester GR, Kinne R, Mueller-Ladner U, Muller B, Haupl T. Synovitis score: discrimination between chronic low-grade and high-grade synovitis. Histopathology, 2006; 49(4):358-64; doi:10.1111/j.1365-2559.2006.02508.x 
Kubo M, Matsuda H, Tanaka M, Kimura Y,Okuda H, Higashino M, Tani T, Namba K, Arichi S. Studies on scutellariae radix. Vii. Antiarthritic and anti-inflammatory actions of methanolic extract and flavonoid components from scutellariae radix. Chem Pharm Bull, 1984; 32(7):27249; doi:10.1248/cpb.32.2724

Latha RM, Geetha T, Varalakshmi P. Effect of vernonia cinerea less flower extract in adjuvant-induced arthritis. Gen Pharmacol, 1998; 31(4):601-6; doi:10.1016/S0306-3623(98)00049-4

Li, J, Ke T, He C, Cao W, Wei M, Zhang L, Zhang JX, Wang W,Ma J, Wang ZR. The anti-arthritic effects of synthetic melittin on the complete freund's adjuvant-induced rheumatoid arthritis model in rats. Am J Chin Med, 2010; 38(06):1039-49; doi:10.1142/S0192415X10008457

Li R, Li J, Cai L, Hu Cm, Zhang L. Suppression of adjuvant arthritis by hesperidin in rats and its mechanisms. J Pharm Pharmacol, 2008; 60(2):221-8; doi:10.1211/jpp.60.2.0011

Lin CY, Wang WH, Chen SH, Chang YW, Hung LC, Chen CY, Chen YH. Lipopolysaccharide-induced nitric oxide, prostaglandin e2, and cytokine production of mouse and human macrophages are suppressed by pheophytin-b. Int J Mol Sci, 2017; 18(12):2637; doi:10.3390/ijms18122637

Liu Yl, Lin Hm, Zou R, Wu Jc, Han R, Raymond LN, Reid PF, Qin Zh. Suppression of complete freund's adjuvant-induced adjuvant arthritis by cobratoxin. Acta Pharmacol Sin, 2009; 30(2):219-27: doi:10.1038/aps.2008.20

Lopes Campêlo LM, Moura Gonçalves FC, Feitosa CM, de Freitas RM. Antioxidant activity of citrus limon essential oil in mouse hippocampus. Pharm Biol, 2011; 49(7):709-15: doi:10.3109/13880209.20 10.541924

Lubberts E, van den Bersselaar L, Oppers-Walgreen B, Schwarzenberger P, Coenen-de Roo CJ, Kolls JK, Joosten LA, van den Berg WB. Il-17 promotes bone erosion in murine collagen-induced arthritis through loss of the receptor activator of nf-kb ligand/osteoprotegerin balance. J Immunol, 2003; 170(5):2655-62; doi:10.4049/jimmunol.170.5.2655

Maini R, Taylor P. Anti-cytokine therapy for rheumatoid arthritis. Ann Rev Med, 2000; 51(1):207-29; doi:10.1146/annurev.med.51.1.207

Martel-Pelletier J, Alaaeddine N, Pelletier JP. Cytokines and their role in the pathophysiology of osteoarthritis. Front Biosci, 1999; 4:D694-703.

McCoy JM, Wicks JR, Audoly LP. The role of prostaglandin e2 receptors in the pathogenesis of rheumatoid arthritis. J Clin Invest, 2002; 110(5):651-8; doi:10.1172/JCI15528

McInnes IB, Liew FY. Cytokine networks - towards new therapies for rheumatoid arthritis. NatClin Pract Rheumatol, 2005; 1(1):31-9; doi:10.1038/ncprheum0020

McInnes IB, Schett G. Cytokines in the pathogenesis of rheumatoid arthritis. Nat Rev Immunol, 2007; 7(6):429-42.

McInnes IB, Schett G. The pathogenesis of rheumatoid arthritis. N Eng J Med, 2011; 365(23):2205-19.

Miale J. Reticuloendothelial system-hemopoiesis and cel destruction. Lab Med Hematol, 1972; 1-71.

Miyake Y, Mochizuki M, Okada M, Hiramitsu M, Morimitsu $\mathrm{Y}$, Osawa T. Isolation of antioxidative phenolic glucosides from lemon juice and their suppressive effect on the expression of blood adhesion molecules. Biosci Biotechnol Biochem, 2007; 71(8):1911-19; doi:10.1271/bbb.70115 $1961 ; 86: 414$

Montgomery H, Dymock J. Nitrite assay in tissue fluids. Analyst,

Mossa ATH,Ibrahim FM, Mohafrash SM, Abou Baker DH, El Gengaihi S. Protective effect of ethanolic extract of grape pomace against the adverse effects of cypermethrin on weanling female rats. Evid-Based Complem Altern Med, 2015; 2015:1-10; doi:10.1155/2015/381919

Mythilypriya R, Shanthi P, Sachdanandam P. Efficacy of siddha formulation kalpaamruthaa in ameliorating joint destruction in rheumatoid arthritis in rats. Chem Biol Interact, 2008; 176(2):243-51; doi:10.1016/j. cbi.2008.07.008

Nie NH, Bent DH, Hull CH. Spss: Statistical Package for the Social Sciences, McGraw-Hill, New York, NY, 1970.
Nishikimi M, Rao NA, Yagi K. The occurrence of superoxide anion in the reaction of reduced phenazine methosulfate and molecular oxygen. Biochem Biophys Res Commun, 1972; 46(2):849-54; doi:10.1016/ S0006-291X(72)80218-3

Ohkawa H, Ohishi N, Yagi K. Assay for lipid peroxides in animal tissues by thiobarbituric acid reaction. Anal Biochem, 1979; 95(2):351-8; doi:10.1016/0003-2697(79)90738-3

Olajide OA, Ajayi AM, Wright CW. Anti-inflammatory properties of cryptolepine. Phytotherapy Res, 2009; 23(10):1421-5; doi:10.1002/ptr.2794

Onur Ö, Akıncı A, Akbıyık F, Ünsal I. Elevated levels of nitrate in rheumatoid arthritis. Rheumatol Int, 2001; 20(4):154-8; doi:10.1007/ s002960100105

Paglia DE,Valentine WN. Studies on the quantitative and qualitative characterization of erythrocyte glutathione peroxidase. Trans Res, 1967; 70(1):158-69.

Patel P, Patel D, Patel N. Experimental investigation of anti-rheumatoid activity of pleurotus sajorcaju in adjuvant-induced arthritic rats. Chin J Nat Med, 2012; 10(4):269-74; doi:10.1016/S18755364(12)60054-5

Persson S, Mikulowska A, Narula S, O'garra A, Holmdahl R. Interleukin-10 suppresses the development of collagen type ii-induced arthritis and ameliorates sustained arthritis in rats. Scand J Immunol, 1996; 44(6):607-14; doi:10.1046/j.1365-3083.1996.d01-355.x

Pino JA, Sánchez M. Chemical composition of grapefruit oil concentrates. J Essential Oil Res, 2000; 12(2):167-9. 64-5, 1997

Polunin M. Healing Foods, DK Publishing New York, NY, pp.

Portanova JP, Zhang Y, Anderson GD, Hauser SD, Masferrer JL, Seibert K, Gregory SA, Isakson PC. Selective neutralization of prostaglandin e2 blocks inflammation, hyperalgesia, and interleukin 6 production in vivo. J Exp Med, 1996; 184(3):883-91.

Punnonen J, Aversa G, Cocks BG, McKenzie A, Menon S, Zurawski G, de Waal Malefyt R, de Vries JE. Interleukin 13 induces interleukin 4-independent igg4 and ige synthesis and cd23 expression by human b cells. Proc Natl Acad Sci, 1993; 90(8):3730-4; doi:10.1073/ pnas.90.8.3730

Qiao Y, Xie B, Zhang Y, Zhang Y, Fan G, Yao X, Pan S. Characterization of aroma active compounds in fruit juice and peel oil of jinchen sweet orange fruit (citrus sinensis (1.) osbeck) by gc-ms and gc-o. Molecules, 2008; 13(6):1333-44.

Ramezani M, Nasri S, Yassa N. Antinociceptive and anti-inflammatory effects of isolated fractions from apium graveolens seeds in mice, Pharm Biol 2009; 47(8):740-3; doi:10.1080/13880200902939283

Rangachari M, Mauermann N, Marty RR, Dirnhofer S, Kurrer MO, Komnenovic V, Penninger JM, Eriksson U. T-bet negatively regulates autoimmune myocarditis by suppressing local production of interleukin 17 J Exp Med, 2006; 203(8):2009-19; doi:10.1084/jem.20052222

Rasool M, Sabina EP, Lavanya B. Anti-inflammatory effect of spirulina fusiformis on adjuvant-induced arthritis in mice. Biol Pharm Bull, 2006; 29(12):2483-7; doi:10.1248/bpb.29.2483

Ricciotti E, FitzGerald GA. Prostaglandins and inflammation Arterioscler Thromb Vasc Biol, 2011; 31(5):986-1000; doi:10.1161/ ATVBAHA.110.207449

Rindfleisch JA, Muller D. Diagnosis and management of rheumatoid arthritis. Am Fam Physician, 2005; 72(6):1037-47.

Romagnani S. The th1/th2 paradigm. Immunology Today, 1997; 18(6):263-6; doi: 10.1016/S0167-5699(97)80019-9

Rovenský J, Stančíková M, Rovenská E, Štvrtina S, Štvrtinová V, Švík K. Treatment of rat adjuvant arthritis with flavonoid (detralex ${ }^{\circledR}$ ), methotrexate, and their combination. Ann New York Acad Sci, 2009; 1173(1):798-804; doi:10.1111/j.1749-6632.2009.04618.x

Ruderman E, Crawford J, Maier A, Liu J, Gravallese EM, Weinblatt M. Histologic liver abnormalities in an autopsy series of patients with rheumatoid arthritis. Rheumatology, 1997; 36(2):210-3; doi:10.1093/ rheumatology/36.2.210 
Schmidt-Weber C, Alexander S, Henault L, James L, Lichtman A. Il-4 enhances il-10 gene expression in murine th2 cells in the absence of tcr engagement. J Immunol, 1999; 162(1):238-44.

Schmidt-Weber CB, Akdis M, Akdis CA. Th17 cells in the big picture of immunology. J Allergy Clin Immunol, 2007; 120(2):247-54; doi:10.1016/j.jaci.2007.06.039

Schulze-Koops H, Kalden JR. The balance of th1/th2 cytokines in rheumatoid arthritis. Best Pract Res Clin Rheumatol, 2001; 15(5):67791; doi:10.1053/berh.2001.0187

Sergejeva S, Ivanov S, Lotvall J, Lindén A. Interleukin-17 as a recruitment and survival factor for airway macrophages in allergic airway inflammation. Am J Respir Cell Mol Biol, 2005; 33(3):248-53; doi:10.1165/ remb.2004-0213OC

Seven A, Güzel S, Aslan M, Hamuryudan V. Lipid, protein, DNA oxidation and antioxidant status in rheumatoid arthritis. Clin Biochem, 2008; 41(7):538-43; doi:10.1016/j.clinbiochem.2008.01.029

Shah SUA, Jawed H, Awan SI, Anjum S, Simjee SU. The antiarthritic and immune-modulatory effects of nhag: a novel glucosamine analogue in adjuvant-induced arthritis. BioMed Res Int, 2013; 2013:1-13; doi: $10.1155 / 2013 / 487610$

Singh Y, Khan SA, Owais M, Abbas M, Parvez A, Kamal A. Th1/th2 profile in patients suffering with osteoarthritis and rheumatoid arthritis: an analytical observational study. CHRISMED J Health Res, 2014; 1(4):258; doi:10.4103/2348-3334.142998

Snekhalatha U, Anburajan M, Venkatraman B, Menaka M. Evaluation of complete freund's adjuvant-induced arthritis in a wistar rat model. Zeitschrift für Rheumatologie, 2013; 72(4):375-82; doi:10.1007/ s00393-012-1083-8

Sornasse T, Larenas PV, Davis KA, de Vries JE, Yssel H. Differentiation and stability of $t$ helper 1 and 2 cells derived from naive human neonatal cd4+ t cells, analyzed at the single-cell level. J Exp Med, 1996; 184(2):473-83; doi:10.1084/jem.184.2.473

Stamp LK, Khalilova I, Tarr JM, Senthilmohan R, Turner R, Haigh RC, Winyard PG, Kettle AJ. Myeloperoxidase and oxidative stress in rheumatoid arthritis. Rheumatology, 2012; 51(10):1796-803; doi:10.1093/ rheumatology/kes 193

Stils HF. Adjuvants and antibody production: dispelling the myths associated with freund's complete and other adjuvants. ILAR J, 2005; 46(3):280-93; doi:10.1093/ilar.46.3.280

Sumanth M, Swetha S. Elucidation of mechanism of anti-arthritic action of arthosansar - a polyherbal formulation. Ind J Trad Knowledge, 2012; 11(4):704-13.

Syed KM, Pinals RS. Leukocytosis in rheumatoid arthritis. J Clin Rheumatol, 1996; 2(4):197-202.

Tag HM, Kelany OE, Tantawy HM, Fahmy AA. Potential antiinflammatory effect of lemon and hot pepper extracts on adjuvant-induced arthritis in mice. J Basic Appl Zool, 2014; 67(5):149-57; doi:10.1016/j jobaz.2014.01.003

Tanaka T, Makita H, Kawabata K, Mori H, Kakumoto M, Satoh K, Hara A, Sumida T, Ogawa H. Chemoprevention of azoxymethaneinduced rat colon carcinogenesis by the naturally occurring flavonoids, diosmin and hesperidin. Carcinogenesis, 1997; 18(5):957-65.

Taysi S, Polat F, Gul M, Sari R, Bakan E. Lipid peroxidation, some extracellular antioxidants, and antioxidant enzymes in serum of patients with rheumatoid arthritis. Rheumatol Int, 2002; 21(5):200-4; doi:10.1007/s00296-001-0163-x

Ueki Y, Miyake S, Tominaga Y, Eguchi K. Increased nitric oxide levels in patients with rheumatoid arthritis. J Rheumatol, 1996; 23(2):230 6.

Veselinovic M, Barudzic N, Vuletic M, Zivkovic V, Tomic-Lucic A, Djuric D, Jakovljevic V. Oxidative stress in rheumatoid arthritis patients: relationship to diseases activity. Mol Cell Biochem, 2014; 391(1-2):22532; doi:10.1007/s11010-014-2006-6

Vijayalaxmi A, Bakshi V, Begum N. Anti-arthritic and anti inflammatory activity of beta caryophyllene against freund's complete adjuvant induced arthritis in wistar rats. Bone Rep Recomm, 2015; $1(1): 1-10$.

Williams RO, Mason LJ, Feldmann M, Maini RN. Synergy between anti-cd4 and anti-tumor necrosis factor in the amelioration of established collagen-induced arthritis. Proc Natl Acad Sci, 1994; 91(7):2762-66; doi:10.1073/pnas.91.7.2762

Woods JM, Haines GK, Shah MR, Rayan G, Koch AE. Lowlevel production of interleukin-13 in synovial fluid and tissue from patients with arthritis. Clin Immunol Immunopathol, 1997; 85(2):210-0; doi:10.1006/clin.1997.4441

Yoo SJ, Go E, Kim YE, Lee S, Kwon J. Roles of reactive oxygen species in rheumatoid arthritis pathogenesis. JRheum Dis, 2016;23(6):340-7; doi 07.04/ijaai.195202

Zheng Y, Danilenko DM, Valdez P, Kasman I, Eastham-Anderson $\mathrm{J}$, Wu J, Ouyang W. Interleukin-22, a t h 17 cytokine, mediates il-23induced dermal inflammation and acanthosis. Nature, 2007; 445(7128):648; doi:10.1038/nature05505

\section{How to cite this article:}

Ahmed OM, Ashour MB, Fahim HI, Ahmed NA. The role of Th1/Th2/Th17 cytokines and antioxidant defense system in mediating the effects of lemon and grapefruit peel hydroethanolic extracts on adjuvant-induced arthritis. J App Pharm Sci, 2018; 8(10): 069-081. 